\title{
CATARACT SUTURES*
}

\author{
BY \\ W. L. HUGHES \\ New York
}

Most eye surgeons used no sutures in routine cataract operations 30 years ago, but to-day some type of suturing is almost always used for the wound.

During the last 15 years a great deal has been written on the subject of cataract sutures in regand to the materials from which they are made and the tissue reaction to various substances, and the advantages and disadvantages of various techniques. My criteria for the ideal suture are the following:

(1) They should be fine and pass smoothly through tissue.

(2) They should be dyed to be easily visible for handling and picking up during operations.

(3) They should be sufficiently strong to hold tissues together.

(4) They should be quite flexible and remain so during the operation.

(5) They should produce a small soft knot which can if desired overlie the cornea without damaging it.

(6) They should not loosen after being tied.

(7) The material should not crack or fray during manipulation.

(8) The ends should be soft and lie flat so that they do not stick into or irritate the tissues.

(9) They should produce minimal tissue reaction.

(10) They should disappear spontaneously in about 10 days, leaving no sign of their presence. No further manipulation should be necessary at any time after the operation has been completed.

(11) They should be able to be attached simply and easily, or should come attached to fine sharp needles that will pass through the eye tissues with little resistance.

(12) The junction between the suture and needles should be smooth, not larger than the diameter of the suture, with no protruding shoulders, edges, or ends that will catch on tissues and cause any injury in passing through.

(13) The needles should be tough and not break easily on being grasped with ordinary needle holders now in use.

(14) The needles should be uniformly sharp with a moderately curved, cutting edge.

(15) The most useful length of suture is about 14".

(16) The material should not swell, shrink, or weaken on being soaked in ordinary sterilizing solutions.

(17) The sutures should be capable of being sterilized and re-sterilized without losing any of the above qualities.

(18) They should be easily obtainable and reasonably priced.

\section{Material}

Fine silk was the first material used. This was excellent for the purpose; it was quite fine, its black colour made it stand out well, it was flexible, it knotted well, it was sufficiently strong, and it produced as little reaction as any other suture material, but it had the one disadvantage that it had to be removed and therefore necessitated a second manipulation and anaesthesia of the eye. This was the cause of some apprehension on the part of the patient and even in the most skilful

* Received for publication December 12, 1953. 
hands accidents happened with complications such as springing of the wound, loss of the anterior chamber, and hyphaema.

This led to the search for other materials. Nylon both monofilament and braided had the same objection of nonabsorbability, and the next logical step was, of course, to try the only satisfactory absorbable suture in general use for surgery, viz. catgut. At first 4-0 plain gut was the finest available. These were tried and found to be too coarse; the knots produced were much too large and hard, and produced considerable tissue reaction in experimental eyes. The cooperation of a suture company was obtained, and they produced a 5-0 plain gut suture with which several experiments were conducted to determine the characteristics and tissue reactions of this material in comparison with silk, nylon, and chromicized gut of the same diameter. The experiments of Hughes, Guy, and Romaine (194b) showed that the tissue reaction in the cornea and the sclera was approximately the same (possibly slightly greater for this size gut and the coarse needle supplied) in each case. This was rather surprising for it was expected that the gut suture would produce considerably more tissue reaction than either silk or nylon.

The holding power of the sutures was determined by using a series of different types of suture to close wounds in typical cataract incisions in rabbits; at the end of a varying number of days a fine needle was passed into the vitreous and saline was injected until the intra-ocular pressure reached $80 \mathrm{~mm}$. Hg. It was found that the wounds invariably broke open on the 4th or 5th day regardless of whether nylon, silk, or gut sutures was used.

These experiments encouraged us to proceed further, and two leading suture manufacturers set out to improve on the absorbable suture material and needle available. The need was for a finer suture with a uniformly good needle. It was recognized that the 5-0 plain sutures were too coarse and that the needles provided were not sharp enough for fine cataract work. A 6-0 plain gut suture was produced, but on clinical trial this disappeared in about 4 to 5 days. A mild chromicized gut suture with a sharp needle was then made, and this was found to be superior to those previously tried, as it lasted from 14 to 20 days in cataract cases.

This last type of suture is now being produced by two leading firms and Product $\mathrm{A}^{*}$ and Product $\mathrm{B}+$ were tested in a series of fifty cases. Two mattress sutures were used to close cataract wounds, one of A and one of B was placed at the 10.30 and 1.30 o'clock positions respectively and compared as to quality of needle and material in accordance with the criteria enumerated above. The sutures and needles were found to be similar in most respects with two exceptions:

(1) Product B 6-0 lasted on an average 2 or 3 days longer than Product A (i.e. A lasted 12 to 18 days, $B 14$ to 21 days).

(2) The points of the needles of Product $A$ were on the whole somewhat sharper than those of Product B. This distinction varied as some needles were much sharper and passed through the tissues more easily than others. Occasionally the needle points of both types were dull and the edges not sharp, but on the whole the needles currently supplied by both companies are fairly satisfactory, although they are not as sharp as the hand-ground Swiss needles $\left(\mathrm{C}_{+}^{+}\right)$. The last have the disadvantage that the needle must be threaded, and moderate force is required to bring the eyed end of the needle with the suture through corneal and episcleral tissue; this outweighs the advantage of the additional sharpness of the point when used with gut sutures. 
The sutures at present available do not meet the full requirements for the following reasons:

(1) They are not coloured and are sometimes a little difficult to see quickly while operating. They are dyed with a brown vegetable dye which leaves no trace in the tissues. Some sutures were furnished dyed black with the same type of dye that is customarily used for black silk; most of this dye absorbed but sometimes fine specks remained on the sclera for several months.

(2) They are not quite as flexible as they should be, although Product $\mathrm{A}$ was found to be better in this respect. Soaking for 5-10 minutes in Zephiran 1:5000 helped, but longer soaking weakened them.

(3) They last too long on the average (14-24 days). On the whole the A sutures disappeared 2 or 3 days sooner than the B sutures.

(4) The knots produced are too hard to be placed over the cornea and the cut ends sometimes stick out.

(5) Sometimes the swaging is faulty, the end of the suture sticking out from the seam of the swaging. This has been corrected in the A sutures but it is still met with occasionally in the B sutures.

There is therefore room for improvement in the manufacture of an absorbable suture that will be more flexible, will not lose its strength when soaked in a germicidal solution, whose ends will be soft in the tissues, will tie into soft knots, and will absorb in a shorter time, about 10 days. Despite the lack of some ideal features the present sutures are quite good and have the advantage of absorbability. Spontaneous absorbability is obviously an advantage if other important characteristics are not sacrificed.

Many surgeons felt that the tissue reaction to gut would be greater than that to silk. To test this clinically a series of one hundred cataract cases were done using two sutures, one of 6-0 silk suture, one of an other material; 4-0 plain gut, $6-0$ nylon, 5-0 plain gut, 5-0 chromicized gut, $6-0$ plain gut, and $6-0$ chromicized gut. It was found that $4-0$ plain gut and $5-0$ chromicized gut gave considerable reaction, nylon was about the same as silk, 5-0 plain gut gave slightly more reaction than silk, $6-0$ plain gut and $6-0$ mild chromicized gut gave about the same reaction as silk. It is quite possible that some other absorbable material will be found that will have more advantages and fewer shortcomings.

\section{Technical Considerations}

Many types of cataract wound closure have been tried; the criteria for the proper closure of the 'wound may be summarized as follows:

(1) The cornea and scleral margins of the wound should be accurately approximated and be able to be sealed quickly by the healing process.

(2) The closing effect of the suture should extend along the limbus as far as possible. A mattress suture is thought to be best for this purpose.

(3) The portion of the suture in the cornea should be placed before the eye is opened.

(4) The corneo-scleral loop of the suture should not include the margin of conjunctival epithelium covering the limbus or the edge of a conjunctival flap. 
(5) The closure should be strong enough to resist an intra-ocular pressure of considerable force (at least $80 \mathrm{~mm}$. $\mathrm{Hg}$ was selected as an arbitrary figure) for the first 4 to 5 and preferably 7 to 8 days.

Most of the suturing techniques described in the literature were tried. Any suture, like the direct approximating suture placed across the wound edges at the limbus (whether with or without a small conjunctival flap including the external layer of epithelium), is likely to fold in epithelial cells along the line of the wound: These cells sometimes grow inwards and form cysts or epithelialize the anterior chamber. The typical Stallard suture tended to do this, as did most of the so-called "track" sutures and direct sutures used in the lips of the wound. It has been frequently noticed that a cyst will form on the inside of the cornea directly underneath the fine scar of a limbal suture of this type. The McLean suture avoids this. The Stallard suture, having the advantage of being a pre-placed mattress suture, was used in a series of sixty cases; epithelialization of the anterior chamber was seen in two cases and cyst of the iris in one. These complications were felt to be due to the infolding of the conjunctival edges caused by the suture, thus favouring downgrowth of conjunctival epithelial elements into the wound during the early healing process. If they continue to grow into the anterior chamber they may either seal themselves off and form a cyst or spread out on the inside of the eye and produce an epithelialization of the anterior chamber. That this was most likely the case is suggested by the fact that since the Stallard suture was modified so that the edges of the conjunctival flap are definitely kept out of the wound, no anterior chamber cyst or epithelialization of the anterior chamber have been seen in a series of 250 consecutive cases, and delayed re-formation of the anterior chamber has become a rarity (four cases in this series). The technique of this type of suture

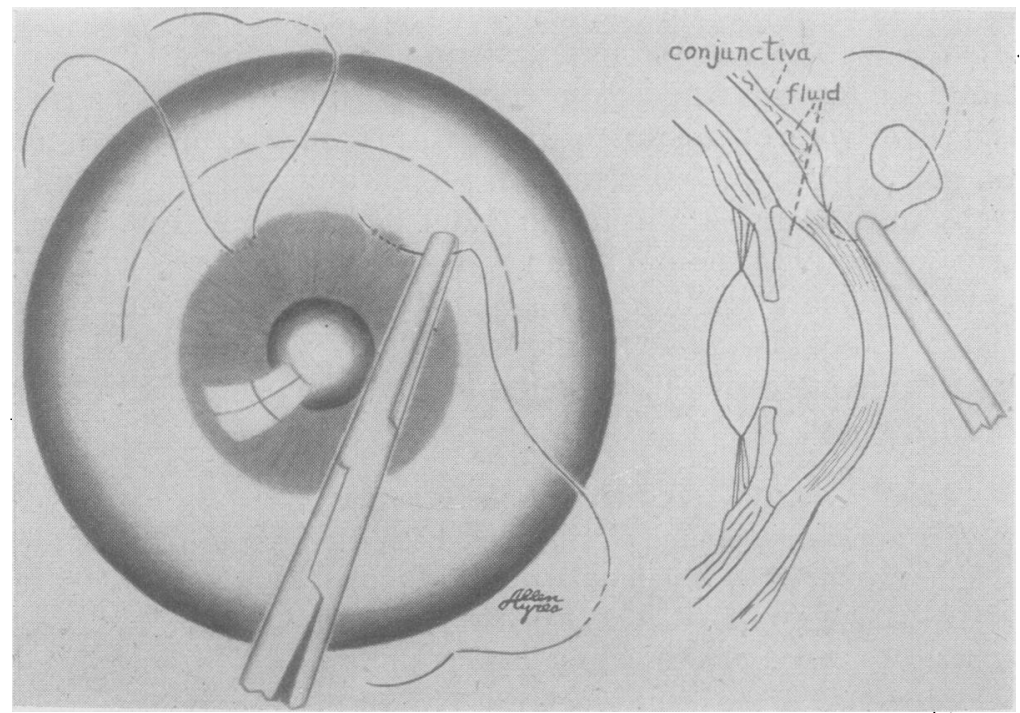

FIG. 1.-Insertion of corneal portion of suture before incision. Ideal conjunctival flap outlined.

preserves the advantages of the mattress type and eliminates some of the disadvantages of the Stallard suture:

(1) Two double-armed 6-0 gut sutures swaged onto a good curved cutting-edge needle are used. Before the incision is made, one end is passed through the cornea 'parallel to 
the limbus just inside the conjunctival attachment for a distance of 1.5 to $2 \mathrm{~mm}$. at a depth of about one third of the corneal thickness (Fig. 1). One end is left much longer than the other. The ends are laid down and the incision made with a 2-mm. conjunctival flap, using a Graefe knife, and enlarging with scissors.

(2) The sutures are then passed through the base of the conjunctival flap. (Fig. 2).

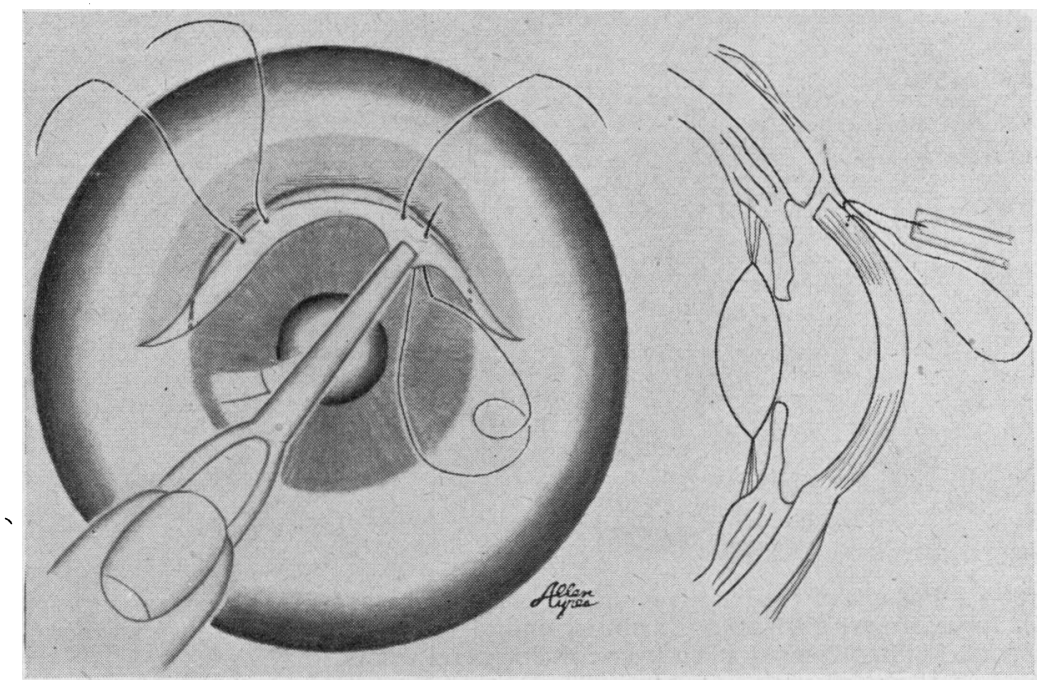

FIG. 2.-After incision sutures are passed through base of flap.

(3) The needle picks up a small amount of sclera and episcleral tissue and comes out through the conjunctival margin above (Fig. 3). The needle on the short end is cut off.

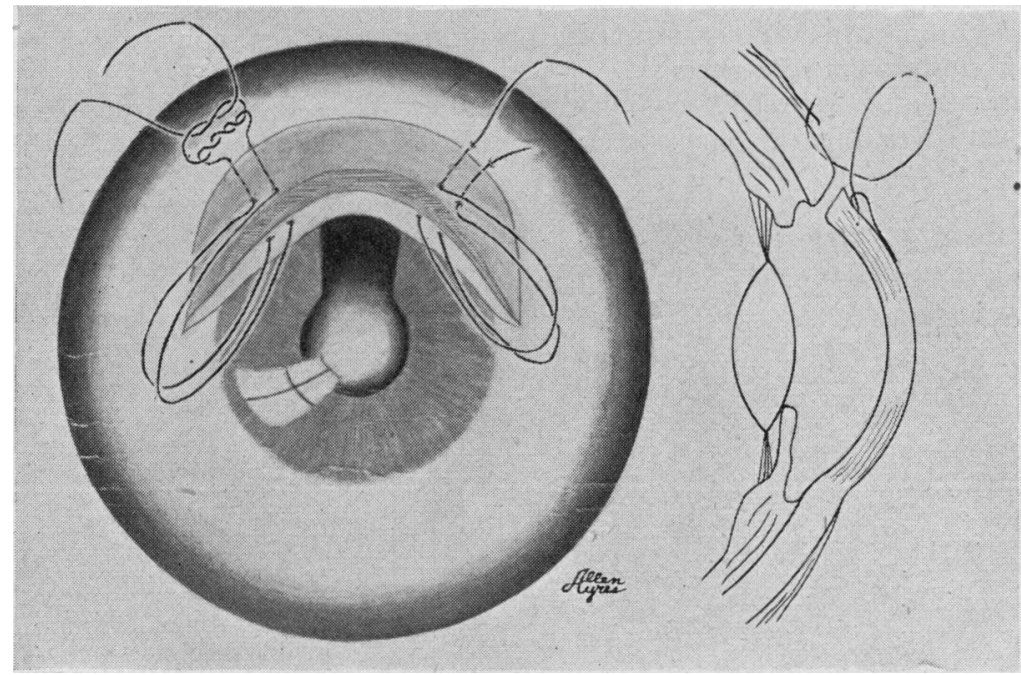

FIG. 3.-Sutures pick up episcleral tissue and emerge in conjunctival margin above.

One turn of a surgical knot is placed.

(4) The first double turn of a surgical knot is placed so that the first part of the knot can be tied quickly at any time.

(5) Immediately on removal of the lens, the sutures are pulled to close the wound snugly 
but not too tightly, to avoid wrinkling the cornea and over-riding the lips of the wound. The second turn of a surgical knot is then tied. (Fig. 4).

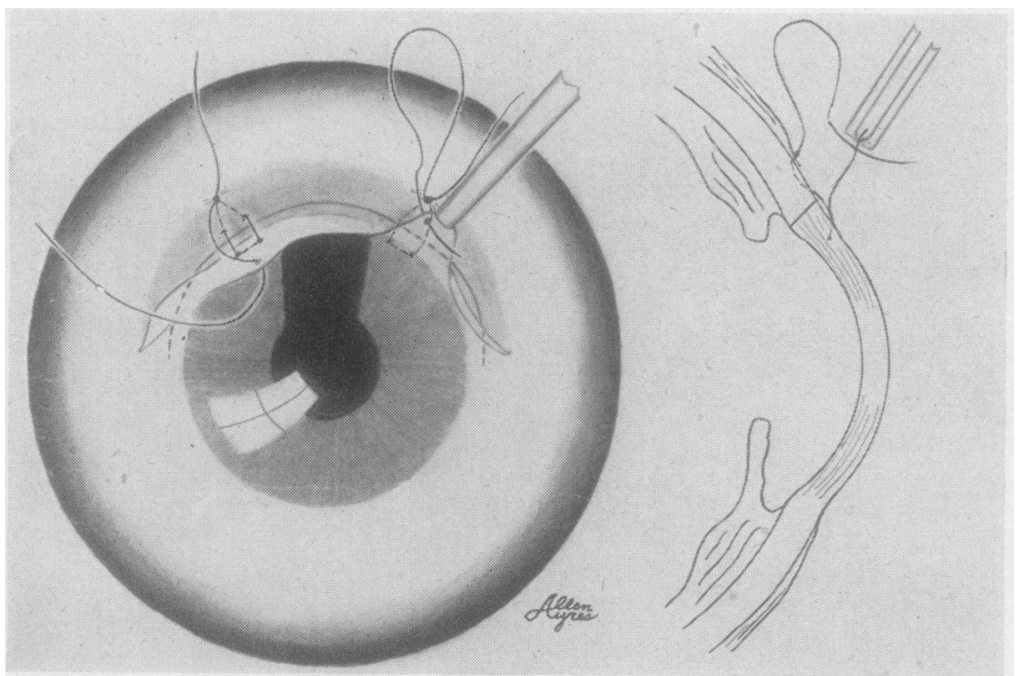

Fig. 4.-Portion of two mattress sutures closing limbal wound drawn up and first two turns of knot tied. Needle on one end of suture is passed through margin of conjunctival flap to draw it up over corneo-scleral wound.

(6) The remaining needle is passed through the margin of the conjunctival flap attached to the cornea, and two more knots are tied over the first ones, bringing this flap up away from the wound and providing a covering flap for the corneo-scleral closure (Figs 4 and 5). The suture is finally cut $2 \mathrm{~mm}$ from the knot, leaving, on the average, a fairly long singlearm suture that can be put away and re-sterilized later by soaking in Zephiran for use in closure of conjunctival wounds in muscle operations, trephines, conjunctivoplasties, or even skin closures in youngsters.

(7) Three small edge-to-edge conjunctival sutures are used, one to approximate the conjunctival edges centrally, and one at each side of the mattress sutures (Fig. 5).

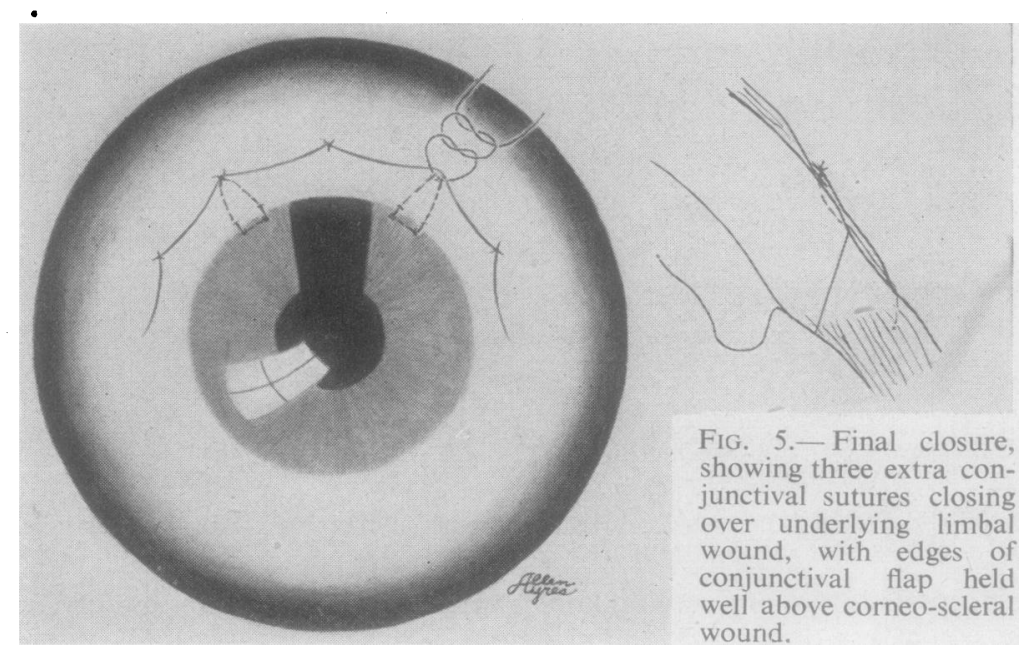


In the type of suture described above, the portion that closes the corneoscleral edges passes underneath the conjunctival flap, the margin of which is later sewn over the wound 2 to $3 \mathrm{~mm}$. above the level of the closure of the deeper part of the wound. This not only keeps this margin away from a position where it might grow down into the limbal wound, but also gives a conjunctival covering as an additional seal over the deep wound, and thus lessens the likelihood of a leaky wound. The results of using this type of suture have justified the slight additional trouble of putting them in.

Dunnington (1951) has shown that downgrowths of the conjunctival epithelium into cataract wounds are not at all infrequent.

It is therefore advantageous to use some type of suture that will serve to keep the conjunctival margins away from the line of the deeper corneo-scleral wound so that it cannot grow down into the wound. A conjunctival flap about 2-3 mm. wide along the entire wound is necessary to assure its proper position away from the deeper wound closure. This type of suture has the following advantages:

(1) The corneal portion is placed before the incision is made.

(2) The remaining portions of the sutures closing the corneo-scleral wound are placed before the lens is removed.

(3) The two mattress-type sutures provide the closure effect over a longer portion of the wound than two single sutures.

(4) Immediate closure of the wound is simply enabled by pulling up the knot; a second knot may then be tied at leisure.

(5) The wound is unprotected only during the relatively safe interval before removal of the lens. The sutures are pulled to close the corneo-scleral wound as the lens is being delivered, thus closing the deep wound immediately behind the emerging lens.

(6) There is no likelihood of the suture being in contact with the aqueous, as often happens with direct sutures (track, McLean, or others) in the lips of the wound. These latter may accurately close the outer part of the wound which is included in the suture but cannot bring the inner lips of the wound together.

(7) Moderate pressure from within tends to approximate the entire wound edges by pressing the wound edges together against the suture, acting like a hoop around a barrel. Of course, severe pressure from within will tend to break open any wound, no matter how it is sewn up.

(8) The conjunctival flap being brought over the deep wound serves to give additional security from without. Often the anterior chamber will be partially or completely reformed before the dressing is applied, and air is usually well retained when placed in the anterior chamber.

(9) The conjunctival flap edges are kept away from the deep wound, almost eliminating the possibility of conjunctival epithelium growing down along the wound.

(10) Suture knots and loose ends are kept away from the cornea, being placed 2-3 mm. above the limbus, where they are cushioned by the conjunctiva and episcleral tissue.

(11) There is separate alignment of the corneo-scleral wound and of the conjunctival edges, giving a double wound closure.

(12) The incidence of anterior chamber cysts, epithelialization of the anterior chamber, leaky wounds, and delayed re-formation of the anterior chamber is materially lessened

(13) Since the sutures are absorbable, there are never any complications incident to the removal of sutures, ${ }^{*}$ such as haemorrhage into the anterior chamber, loss of anterior

*The technique described may of course be used with silk if desired, but in that case this roint dces not $\varepsilon$ pply. 
chamber, accidental opening of the wound, pain, or the anticipation of pain by the patient.

(14) The tissue reaction in the eye is the same as with a suture of any other material (silk, nylon, cotton, etc.).

Roberts (1952) describes a suture somewhat similar in that there is separate closure of the scleral wound with a conjunctival flap brought over the corneoscleral closure. In this technique three 6-0 chromic sutures are tied so that their knots are placed under the conjunctival flap. In this location they might erode through the conjunctival flap and persist too long, whereas in the technique described above the knots are cast off externally.

In this discussion I have purposely not mentioned the use of fibrin as I do not feel that this material is satisfactory for sutures. Most normal cases can be done without sutures, but support to the wound is really necessary when some complication such as increased pressure from within, structures from within tending to extrude into the wound, e.g., iris bulging hyaloid, or loose vitreous in the wound. The union afforded by fibrin is not firm enough to withstand any real pressure from within and if vitreous is in the wound the fibrin union is totally ineffective. One is then faced with placing sutures in the lips of a wound bathed in vitreous rather than having sutures already in place ready to pull up to close the wound immediately behind the emerging lens.

\section{Conclusion}

It is felt that the absorbable type of suture, swaged on a good needle, and used in the manner described above, gives a satisfactory closure for cataract wounds, fulfilling most of the criteria for an ideal suture and permitting the use of the technique outlined above. It is hoped that further research will lead to the development of the perfect suture material.

\section{REFERENCES}

Dunnington, J. H. (1951). Amer. J. Ophthal., 34, 36.

Hughes, W. L., GuY, L. P., and RomaIne, H. H. (1944). Arch. Ophthal. (Chicago), $32,362$. ROBERTS, W. (1952). Amer. J. Ophthal., 35, 1459. 